\title{
The relationship of serum alanine aminotransferase normal-range levels to arterial stiffness and metabolic syndrome in non-drinkers and drinkers: a Chinese community-based analysis
}

\author{
Shihui Fu ${ }^{1,2+}$, Ying Lin ${ }^{2 \dagger}$, Leiming Luo ${ }^{1 *}$ and Ping Ye ${ }^{1 *}$
}

\begin{abstract}
Background: Few studies have investigated the relationship between carotid-femoral pulse wave velocity (cfPWW) and serum alanine aminotransferase (ALT) normal-range levels across the world. The current analysis was designed to explore the relationship of serum ALT normal-range levels to CfPWV and metabolic syndrome (Mets) in nondrinkers and drinkers in a Chinese community-dwelling population.

Methods: There were 2202 participants with serum ALT levels within normal range enrolled for the current analysis. Results: Median (range) age of participants was 53 (18-96) years, 51.5\% were males, and 31.2\% were drinkers. Prevalence of Mets was 29.4\%. Median (range) of cfPWV was 10.1 (2.4-32.7) m/s. Hazard ratios for prevalence of Mets, central obesity and high triglyceride significantly increased with elevated levels of serum ALT in both nondrinkers and drinkers ( $p<0.05$ for all). Hazard ratios for prevalence of cfPWV $>10 \mathrm{~m} / \mathrm{s}$, high blood pressure and high blood glucose significantly increased with elevated levels of serum ALT in non-drinkers ( $p<0.05$ for all), but not in drinkers ( $p \geq 0.05$ for all).

Conclusions: In a Chinese community-dwelling population, prevalence of Mets and its components (including central obesity and high TG) increased with an elevation in serum ALT levels within normal range in both nondrinkers and drinkers, while cfPWV and other components of Mets, such as high blood pressure and glucose, increased with an elevation in serum ALT levels in non-drinkers, but not in drinkers.
\end{abstract}

Keywords: Alanine aminotransferase, Alcohol intake, Arterial stiffness, Chinese community-based analysis, Metabolic syndrome

\section{Background}

Prevalence of Metabolic syndrome (Mets) is rapidly increasing in parallel with an elevation in serum levels of alanine aminotransferase (ALT) [1]. Globally, measurements of serum ALT levels are the most commonly used test to identify patients suffering from liver disease. Serum ALT levels also act as an important marker for

\footnotetext{
* Correspondence: Ileim@sina.com; sci301@126.com

${ }^{\dagger}$ Equal contributors

'Department of Geriatric Cardiology, Chinese People's Liberation Army General Hospital, Beijing 100853, China

Full list of author information is available at the end of the article
}

liver function and disease severity [2]. In previous studies, Mets has been shown to be related to serum ALT levels [3-6]. However, published studies generally include clinical patients with elevated levels of serum ALT, and there is little information on the relationship between Mets and serum ALT levels within normal range in Chinese community-dwelling population [7].

Carotid-femoral pulse wave velocity (cfPWV) is a widely accepted measure of central arterial stiffness, which is commonly used as a marker of atherosclerosis [2]. However, to our knowledge, few studies have investigated the relationship between cfPWV and serum ALT 
levels within normal range across the world. Moreover, alcohol intake has an important effect on the relationship of serum ALT levels to cfPWV and Mets. Therefore, the current analysis was designed to explore the relationship of serum ALT levels within normal range to cfPWV, Mets and its components in non-drinkers and drinkers in a Chinese community-dwelling population.

\section{Methods}

\section{Study population}

A stratified cluster sampling method was used in the selection of participants through a routine health check-up in Beijing between May 2007 and July 2009. In the first layer of sampling, three out of 18 Beijing districts were selected (Fengtai, Shijingshan and Daxing); in the second layer of sampling, four communities were selected from the three selected districts; in the third layer of sampling, participants aged 18 years or over were selected from the four selected communities. The current analysis was conducted in 2476 Chinese community-dwelling participants. After the exclusion of 103 participants with positive hepatitis virus antigens, there were 2373 participants with negative hepatitis virus antigens. After the exclusion of 171 participants with serum ALT levels $>40 \mathrm{U} / \mathrm{L}$, other 2202 participants were enrolled for the final analysis (Fig. 1).

\section{Participant interview and serological test}

Participants were interviewed by trained physicians at the local health service center. Systolic and diastolic blood pressure (SBP and DBP) were measured twice for each participant in the sitting position, with an interval of at least 1 min between measurements, using a standard sphygmomanometer (Yuwell medical equipment \& supply Co., Ltd., Jiangsu, China). A cuff of appropriate size was placed on the right arm of participants, after a rest period for at least $5 \mathrm{~min}$. In order to assess central obesity, waist circumference (WC) was measured from the standing participants midway between the lowest rib and iliac crest using a soft tape. Blood samples were taken from participants for serological tests. Overnight fasting serum samples were tested by qualified personnel in our central laboratory. Fasting blood glucose (FBG), triglyceride (TG), high-density lipoprotein-cholesterol (HDL-c), ALT and hepatitis virus antigens were assessed using the assays (Roche Products Ltd, Basel, Switzerland) on a full automatic biochemical autoanalyser (COBAS 6000; Roche Products Ltd, Basel, Switzerland).

\section{Diagnostic criteria}

Central obesity was defined as $W C \geq 85 \mathrm{~cm}$ in males and $\geq 80 \mathrm{~cm}$ in females, as recommended by Guidelines on Preservation and Control Overweight and Obesity in Chinese Adults [8]. Based on new International Diabetes Federation definition, Mets was diagnosed in participants exhibiting central obesity plus at least two of the following criteria: 1$)$ high blood pressure $(\geq 130 / 85 \mathrm{mmHg}$ and/or taking anti-hypertensive medication), 2) high blood glucose $(\geq 5.6 \mathrm{mmol} / \mathrm{L}$ and/or taking anti-diabetic medication), 3) high TG ( $\geq 1.7 \mathrm{mmol} / \mathrm{L})$, and 4) low HDL-c (males: < $1.0 \mathrm{mmol} / \mathrm{L}$; females: < $1.3 \mathrm{mmol} / \mathrm{L}$ ) [9]. Diabetes mellitus (DM) was diagnosed as $\mathrm{FBG} \geq 7.0 \mathrm{mmol} / \mathrm{L}$ and/or taking anti-diabetic medication. Hypertension was diagnosed as blood pressure $\geq 140 / 90 \mathrm{mmHg}$ and/or taking anti-hypertensive medication. Drinkers were defined as participants consuming at least $30 \mathrm{~g}$ of alcohol per week for at least 1 year [10].

\section{Arterial stiffness analysis}

Arterial stiffness was assessed through automated measurements of cfPWV using a Complior Colson device (Créatech, Besançon, France; for technical characteristics see [11]) in the morning, in a quiet environment, at stable temperature. Participants were assessed in the

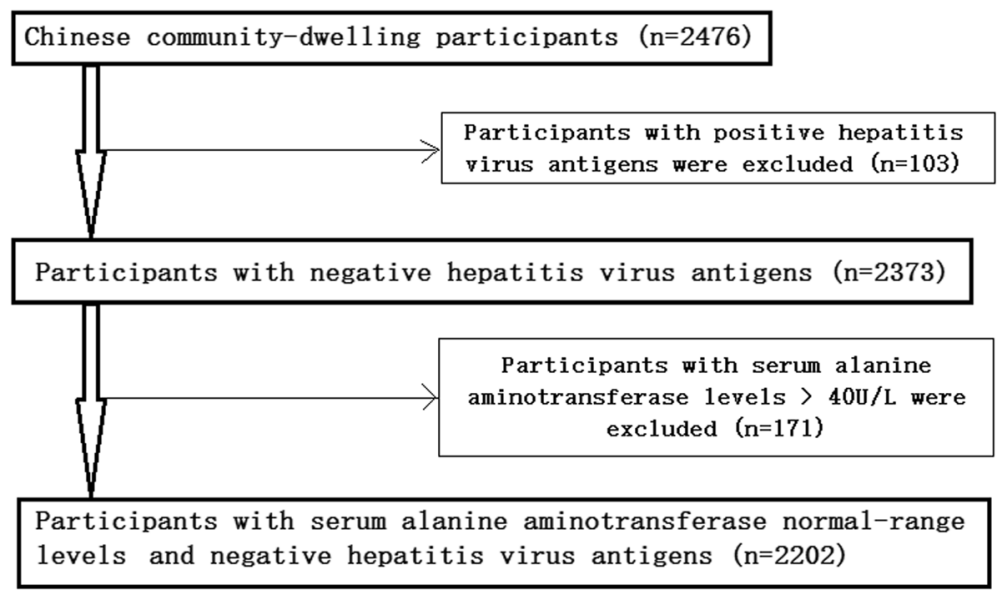

Fig. 1 Flow chart of study participant selection process 
supine position, after resting for at least $5 \mathrm{~min}$. cfPWV along the artery was measured using two strain gauge transducers (TY-306 pressure-sensitive transducer, Fukuda Denshi Co, Tokyo, Japan), fixed transcutaneously over the course of the arteries, separated by a known distance; the right-side carotid and femoral arteries were used. After waveforms of sufficient quality were recorded, the digitization process was initiated by the operator, and the automatic calculation of the time delay between two upstrokes was obtained. Measurements were repeated over ten cardiac cycles, and the mean value was used in the final analysis. cfPWV was calculated from the measurement of the pulse transit time and distance traveled by the pulse between the two recording sites (measured on the surface of the body, in meters), according to the following formula: cfPWV $(\mathrm{m} / \mathrm{s})=$ distance $(\mathrm{m}) /$ transit time $(\mathrm{s})$.

\section{Statistical analysis}

Participants were firstly divided into drinkers and nondrinkers, and then subdivided according to the quartiles of serum ALT levels within normal range. In all subgroups, parameters were expressed as mean and standard deviation (in the case of continuous variables with normal distribution), median and interquartile range (in the case of continuous variables with skewed distribution), and number of participants and percentage (in the case of categorical variables). Age, sex, cfPWV, Mets and its components were compared across the subgroups. One-way analysis of variance, Kruskal-Wallis test and $x^{2}$ test were used to respectively compare differences in continuous variables with normal distribution, continuous variables with skewed distribution and categorical variables. Hazard ratios for prevalence of cfPWV $>10 \mathrm{~m} / \mathrm{s}$, Mets and its components with elevated levels of serum ALT were assessed using logistic regression models. Statistical analysis was performed on Statistical Package for Social Sciences (SPSS) version 17.0 (SPSS Inc, Chicago, IL., USA), and statistical significance was defined as a twotailed $p$-value $<0.05$.

\section{Results}

Median (range) age of participants was 53 (18-96) years. Among them, $51.5 \%$ were males, and $31.2 \%$ were drinkers. Median (range) of serum ALT levels was 16.4 (2.0-40.0) U/L. Prevalence of Mets was 29.4\%. Median (range) of cfPWV was 10.1 (2.4-32.7) m/s. In non-drinkers (Table 1), serum ALT levels were significantly related to age, sex, WC, central obesity, hypertension, DM, SBP, DBP, high blood pressure, TG, high TG, HDL-c, FBG, high blood glucose, Mets, cfPWV and cfPWV $>10 \mathrm{~m} / \mathrm{s}$ $(p<0.05$ for all). In drinkers (Table 2$)$, serum ALT

Table 1 Characteristics of non-drinkers according to the quartiles of serum ALT levels

\begin{tabular}{|c|c|c|c|c|c|}
\hline Characteristics & $\begin{array}{l}\text { Quartile } 1 \\
\leq 10 \text { U/L } \\
(n=200)\end{array}$ & $\begin{array}{l}\text { Quartile } 2 \\
11-20 \cup / L \\
(n=871)\end{array}$ & $\begin{array}{l}\text { Quartile } 3 \\
21-30 \cup / L \\
(n=340)\end{array}$ & $\begin{array}{l}\text { Quartile } 4 \\
31-40 \cup / L \\
(n=104)\end{array}$ & $P$-value \\
\hline Age (year) & $46(32-63)$ & $60(48-70)$ & $58(50-67)$ & $55(48-63)$ & $<0.001$ \\
\hline Males (\%) & $32(16.0)$ & 269(30.9) & $148(43.5)$ & $47(45.2)$ & $<0.001$ \\
\hline Central obesity (\%) & $63(31.5)$ & $525(60.3)$ & $241(70.9)$ & $77(74.0)$ & $<0.001$ \\
\hline WC (cm) & $75(69-82)$ & $84(77-90)$ & $87(81-94)$ & $87(81-95)$ & $<0.001$ \\
\hline Hypertension (\%) & $43(21.5)$ & $328(37.7)$ & $170(50.0)$ & $46(44.2)$ & $<0.001$ \\
\hline DM (\%) & $13(6.5)$ & 139(16.0) & $61(17.9)$ & 19(18.3) & 0.002 \\
\hline $\mathrm{SBP}(\mathrm{mmHg})$ & 115(105-129) & 124(112-137) & 128(118-141) & $126(116-140)$ & $<0.001$ \\
\hline $\mathrm{DBP}(\mathrm{mmHg})$ & $71(66-78)$ & $73(68-80)$ & $79(70-84)$ & $77(70-85)$ & $<0.001$ \\
\hline High blood pressure (\%) & $58(29.0)$ & $427(49.0)$ & $210(61.8)$ & $57(54.8)$ & $<0.001$ \\
\hline TG $(\mathrm{mmol} / \mathrm{L})$ & $0.98(0.77-1.36)$ & 1.35(0.98-1.89) & $1.54(1.11-2.20)$ & $1.79(1.18-2.42)$ & $<0.001$ \\
\hline High TG (\%) & 24(12.0) & $281(32.3)$ & 149(43.8) & $53(51.0)$ & $<0.001$ \\
\hline $\mathrm{HDL}-\mathrm{c}(\mathrm{mmol} / \mathrm{L})$ & $1.54(1.26-1.79)$ & $1.40(1.20-1.64)$ & $1.30(1.14-1.51)$ & $1.29(1.08-1.52)$ & $<0.001$ \\
\hline Low HDL-c (\%) & $49(24.5)$ & $237(27.2)$ & $107(31.5)$ & $36(34.6)$ & 0.129 \\
\hline FBG $(\mathrm{mmol} / \mathrm{L})$ & $4.80(4.48-5.06)$ & $4.89(4.50-5.38)$ & $4.95(4.61-5.43)$ & $5.10(4.72-5.55)$ & $<0.001$ \\
\hline High blood glucose (\%) & $21(10.5)$ & 199(22.8) & $85(25.0)$ & $29(27.9)$ & $<0.001$ \\
\hline Mets (\%) & $22(11.0)$ & $260(29.9)$ & 149(43.8) & $51(49.0)$ & $<0.001$ \\
\hline $\operatorname{cfPWV}(\mathrm{m} / \mathrm{s})$ & $9.1(8.0-10.9)$ & 10.3(9.0-12.4) & $10.5(9.3-12.3)$ & 10.4(9.0-11.9) & $<0.001$ \\
\hline $\mathrm{cfPWV}>10 \mathrm{~m} / \mathrm{s}$ & $66(33.0)$ & $479(55.0)$ & 213(62.6) & $55(52.9)$ & $<0.001$ \\
\hline
\end{tabular}

Abbreviations: $A L T$ alanine aminotransferase, WC waist circumference, DM diabetes mellitus, SBP systolic blood pressure, DBP diastolic blood pressure, $T G$ triglyceride, $H D L-c$ high-density lipoprotein-cholesterol, FBG fasting blood glucose, Mets metabolic syndrome, cfPWV carotid-femoral pulse wave velocity 
Table 2 Characteristics of drinkers according to the quartiles of serum ALT levels

\begin{tabular}{|c|c|c|c|c|c|}
\hline Characteristics & $\begin{array}{l}\text { Quartile } 1 \\
\leq 10 \cup / L \\
(n=57)\end{array}$ & $\begin{array}{l}\text { Quartile } 2 \\
11-20 \cup / L \\
(n=364)\end{array}$ & $\begin{array}{l}\text { Quartile } 3 \\
21-30 \cup / L \\
(n=187)\end{array}$ & $\begin{array}{l}\text { Quartile } 4 \\
31-40 \cup / L \\
(n=79)\end{array}$ & $P$-value \\
\hline Age (year) & $36(31-57)$ & $43(32-58)$ & $40(31-54)$ & $40(32-54)$ & 0.331 \\
\hline Males (\%) & 45(78.9) & $337(92.6)$ & 180(96.3) & $77(97.5)$ & $<0.001$ \\
\hline Central obesity (\%) & 19(33.3) & $212(58.2)$ & 133(71.1) & $61(77.2)$ & $<0.001$ \\
\hline$W C(\mathrm{~cm})$ & $80(72-87)$ & $86(80-91)$ & 89(84-93) & $88(85-95)$ & $<0.001$ \\
\hline Hypertension (\%) & $9(15.8)$ & $101(27.7)$ & $48(25.7)$ & 23(29.1) & 0.262 \\
\hline DM (\%) & $3(5.3)$ & $21(5.8)$ & $10(5.3)$ & 11(13.9) & 0.093 \\
\hline $\mathrm{SBP}(\mathrm{mmHg})$ & 118(111-127) & 123(116-135) & 125(115-134) & 123(117-137) & 0.011 \\
\hline $\mathrm{DBP}(\mathrm{mmHg})$ & $71(67-78)$ & $76(70-81)$ & $77(71-84)$ & $77(71-85)$ & 0.002 \\
\hline High blood pressure (\%) & 15(26.3) & 138(37.9) & $77(41.2)$ & $35(44.3)$ & 0.150 \\
\hline $\mathrm{TG}(\mathrm{mmol} / \mathrm{L})$ & $0.93(0.75-1.24)$ & $1.28(0.93-1.74)$ & $1.69(1.14-2.37)$ & $1.74(1.25-2.67)$ & $<0.001$ \\
\hline High TG (\%) & $4(7.0)$ & $99(27.2)$ & $91(48.7)$ & $45(57.0)$ & $<0.001$ \\
\hline $\mathrm{HDL}-\mathrm{c}(\mathrm{mmol} / \mathrm{L})$ & $1.55(1.36-1.78)$ & $1.35(1.14-1.56)$ & $1.27(1.08-1.48)$ & $1.25(1.01-1.49)$ & $<0.001$ \\
\hline Low HDL-c (\%) & $1(1.8)$ & $44(12.1)$ & $35(18.7)$ & 18(22.8) & 0.001 \\
\hline FBG $(\mathrm{mmol} / \mathrm{L})$ & $4.76(4.40-5.12)$ & $4.85(4.54-5.12)$ & $4.98(4.61-5.27)$ & $4.95(4.52-5.30)$ & 0.030 \\
\hline High blood glucose (\%) & $5(8.8)$ & $40(11.0)$ & $25(13.4)$ & $17(21.5)$ & 0.060 \\
\hline Mets (\%) & $3(5.3)$ & $73(20.1)$ & $55(29.4)$ & $35(44.3)$ & $<0.001$ \\
\hline $\operatorname{cfPWV}(\mathrm{m} / \mathrm{s})$ & $9.4(8.5-11.4)$ & $9.7(8.7-11.3)$ & $9.5(8.7-10.7)$ & $9.9(8.8-11.2)$ & 0.516 \\
\hline $\mathrm{cfPWV}>10 \mathrm{~m} / \mathrm{s}$ & 21(36.8) & $166(45.6)$ & $68(36.4)$ & $35(44.3)$ & 0.161 \\
\hline
\end{tabular}

Abbreviations: $A L T$ alanine aminotransferase, WC waist circumference, DM diabetes mellitus, SBP systolic blood pressure, DBP diastolic blood pressure, TG triglyceride, $H D L-c$ high-density lipoprotein-cholesterol, FBG fasting blood glucose, Mets metabolic syndrome, cfPWV carotid-femoral pulse wave velocity

levels were significantly related to sex, WC, central obesity, SBP, DBP, TG, high TG, HDL-c, low HDL-c, FBG and Mets $(p<0.05$ for all).

Hazard ratios for prevalence of Mets, central obesity and high TG significantly increased with elevated levels of serum ALT in both non-drinkers and drinkers (Table $3 ; p<0.05$ for all). Hazard ratios for prevalence of cfPWV $>10 \mathrm{~m} / \mathrm{s}$, high blood pressure and high blood glucose significantly increased with elevated levels of serum ALT in non-drinkers $(p<0.05$ for all), but not in drinkers $(p \geq 0.05$ for all). Hazard ratios for low HDL-c $(p<0.05$ for all) significantly increased with elevated levels of serum ALT in drinkers, but not in non-drinkers $(p \geq 0.05$ for all).

\section{Discussion}

Prevalence of Mets is rapidly increasing in parallel with an elevation in serum ALT levels [1]. Serum ALT levels are widely used to monitor liver function, and patients with Mets often display elevated levels of serum ALT $[12,13]$. Previous studies have suggested that Mets can be viewed as a strong risk factor for an elevation in serum ALT levels [3-6]. However, few community-based studies have addressed the relationship between Mets and serum ALT levels within normal range in a Chinese community-dwelling population. In both non-drinkers and drinkers, the current analysis revealed that prevalence of Mets increased with an elevation in serum ALT levels. In both preclinical population and clinical patients, insulin resistance is an essential condition for the accumulation of liver fat and plays a key role in the development of Mets [14, 15]. Giving the relationship between Mets and serum ALT levels suggested by the current analysis, an elevation in serum ALT levels should receive more attention in clinical practice, as a factor not only reflecting change of liver fat, but also relating to insulin resistance [1].

Regarding the components of Mets, the current analysis showed that central obesity and high TG become more common as serum ALT levels increased, regardless of alcohol intake [16]. Several studies have demonstrated that change in lipid metabolism has important effects on liver insulin resistance and serum ALT levels [17]. Other studies have also suggested that weight control is as important as improving lipid metabolism on controlling insulin resistance and normalizing serum ALT levels [18-21]. Compared with adipose tissue in other body parts, visceral adipose tissue is more resistant to insulin, and hyperinsulinemia promotes the liver lipogenesis and raises the serum ALT levels [22, 23]. As for other components of Mets, the current analysis showed that prevalence 
Table 3 Hazard ratios for prevalence of cfPWV, Mets and its components with an elevation in serum ALT levels

\begin{tabular}{|c|c|c|c|c|c|}
\hline \multirow[t]{2}{*}{ Serum ALT levels } & & \multicolumn{2}{|l|}{ Non-drinkers } & \multicolumn{2}{|l|}{ Drinkers } \\
\hline & & $\mathrm{HR}(95 \% \mathrm{Cl})$ & $P$-value & $\mathrm{HR}(95 \% \mathrm{Cl})$ & $P$-value \\
\hline \multirow[t]{4}{*}{ Mets } & $\leq 10 \mathrm{U} / \mathrm{L}$ & 1 & & 1 & \\
\hline & $11-20 \mathrm{U} / \mathrm{L}$ & $3.443(2.160-5.487)$ & $<0.001$ & $4.515(1.373-14.851)$ & $<0.001$ \\
\hline & $21-30 \mathrm{U} / \mathrm{L}$ & $6.312(3.859-10.324)$ & $<0.001$ & $7.500(2.249-25.011)$ & $<0.001$ \\
\hline & $31-40 \mathrm{U} / \mathrm{L}$ & 7.786(4.331-13.996) & $<0.001$ & $14.318(4.125-49.699)$ & $<0.001$ \\
\hline \multirow[t]{4}{*}{ Central obesity } & $\leq 10 \mathrm{U} / \mathrm{L}$ & 1 & & 1 & \\
\hline & $11-20 \mathrm{U} / \mathrm{L}$ & $3.300(2.377-4.579)$ & $<0.001$ & $2.789(1.548-5.026)$ & 0.001 \\
\hline & $21-30 \mathrm{U} / \mathrm{L}$ & $5.294(3.623-7.734)$ & $<0.001$ & 4.926(2.610-9.296) & $<0.001$ \\
\hline & $31-40 \mathrm{U} / \mathrm{L}$ & $6.202(3.649-10.539)$ & $<0.001$ & $6.778(3.165-14.512)$ & $<0.001$ \\
\hline \multirow[t]{4}{*}{ High TG } & $\leq 10 \mathrm{U} / \mathrm{L}$ & 1 & & 1 & \\
\hline & $11-20 \mathrm{U} / \mathrm{L}$ & $3.493(2.228-5.475)$ & $<0.001$ & $4.950(1.746-14.035)$ & 0.003 \\
\hline & $21-30 \mathrm{U} / \mathrm{L}$ & $5.721(3.550-9.220)$ & $<0.001$ & $12.560(4.369-36.107)$ & $<0.001$ \\
\hline & $31-40 \mathrm{U} / \mathrm{L}$ & $7.621(4.292-13.532)$ & $<0.001$ & $17.537(5.782-53.191)$ & $<0.001$ \\
\hline \multirow[t]{4}{*}{ Low HDL-c } & $\leq 10 \mathrm{U} / \mathrm{L}$ & 1 & & 1 & \\
\hline & $11-20 \mathrm{U} / \mathrm{L}$ & $1.152(0.808-1.643)$ & 0.435 & $7.700(1.040-57.029)$ & 0.046 \\
\hline & $21-30 \mathrm{U} / \mathrm{L}$ & $1.415(0.953-2.101)$ & 0.085 & $12.895(1.726-96.357)$ & 0.013 \\
\hline & $31-40 \mathrm{U} / \mathrm{L}$ & $1.631(0.973-2.735)$ & 0.063 & $16.525(2.136-127.859)$ & 0.007 \\
\hline \multirow[t]{4}{*}{ High blood pressure } & $\leq 10 \mathrm{U} / \mathrm{L}$ & 1 & & 1 & \\
\hline & $11-20 \mathrm{U} / \mathrm{L}$ & $2.355(1.688-3.285)$ & $<0.001$ & 1.710(0.914-3.199) & 0.093 \\
\hline & $21-30 \mathrm{U} / \mathrm{L}$ & $2.969(1.815-4.858)$ & $<0.001$ & $1.960(1.016-3.783)$ & 0.045 \\
\hline & $31-40 \mathrm{U} / \mathrm{L}$ & $3.955(2.716-5.758)$ & $<0.001$ & $2.227(1.065-4.659)$ & 0.033 \\
\hline \multirow[t]{4}{*}{ High blood glucose } & $\leq 10 \mathrm{U} / \mathrm{L}$ & 1 & & 1 & \\
\hline & $11-20 \mathrm{U} / \mathrm{L}$ & $2.524(1.564-4.075)$ & $<0.001$ & $1.284(0.484-3.403)$ & 0.615 \\
\hline & $21-30 \mathrm{U} / \mathrm{L}$ & $2.841(1.699-4.753)$ & $<0.001$ & $1.605(0.585-4.405)$ & 0.358 \\
\hline & $31-40 \mathrm{U} / \mathrm{L}$ & $3.296(1.768-6.145)$ & $<0.001$ & $2.852(0.985-8.256)$ & 0.053 \\
\hline \multirow[t]{4}{*}{ cfPWV > $10 \mathrm{~m} / \mathrm{s}$} & $\leq 10 \mathrm{U} / \mathrm{L}$ & 1 & & 1 & \\
\hline & $11-20 \mathrm{U} / \mathrm{L}$ & $2.481(1.795-3.429)$ & $<0.001$ & $1.437(0.808-2.558)$ & 0.217 \\
\hline & $21-30 \mathrm{U} / \mathrm{L}$ & $3.405(2.358-4.918)$ & $<0.001$ & 0.980(0.530-1.812) & 0.948 \\
\hline & $31-40 \mathrm{U} / \mathrm{L}$ & $2.279(1.403-3.701)$ & 0.001 & $1.364(0.679-2.740)$ & 0.384 \\
\hline
\end{tabular}

Abbreviations: cfPWV carotid-femoral pulse wave velocity, Mets metabolic syndrome, $A L T$ alanine aminotransferase, $H R$ hazard ratio, $C l$ confidential interval, TG triglyceride, $H D L-c$ high-density lipoprotein-cholesterol

of high blood pressure and glucose increased with an elevation in serum ALT levels in non-drinkers, but not in drinkers. In other words, the relationship of serum ALT levels to high blood pressure and glucose was dissimilar in participants with and without alcohol intake. The current analysis confirmed the empirical knowledge in clinical practice, and demonstrated that alcohol intake can increase the enzyme activity of ALT in the liver, with important effects on the relationship between different components of Mets and serum ALT levels. However, further studies are needed to clarify the potential relationship of serum ALT levels to high blood pressure and glucose.

To our knowledge, few community-based studies have attempted to determine the possible relationship between cfPWV and serum ALT levels within normal range across the world. Therefore, another important finding of the current analysis was the relationship between cfPWV and serum ALT levels even within normal range of serum ALT levels in non-drinkers, but not in drinkers. According to the current analysis, reasons for the relationship between cfPWV and serum ALT levels are related to the intermediary role of insulin resistance and Mets. The overlooked relationship between cardiovascular and liver diseases should receive more attention by clinical doctors. Moreover, the current analysis stressed that arterial stiffness is a breakthrough point in exploring the relationship between cardiovascular and liver diseases in both scientific research and clinical practice. 


\section{Conclusions}

In a Chinese community-dwelling population, the current analysis revealed that prevalence of Mets and its components (including central obesity and high TG) increased with an elevation in serum ALT levels within normal range in both non-drinkers and drinkers, while cfPWV and other components of Mets, such as high blood pressure and glucose, increased with an elevation in serum ALT levels in non-drinkers, but not in drinkers.

\section{Abbreviations}

ALT: Alanine aminotransferase; CPPW: Carotid-femoral pulse wave velocity; DBP: Diastolic blood pressure; DM: Diabetes mellitus; FBG: Fasting blood glucose; HDL-c: High-density lipoprotein-cholesterol; Mets: Metabolic syndrome; SBP: Systolic blood pressure; TG: Triglyceride; WC: Waist circumference

\section{Acknowledgments}

We are grateful to all study participants for their participation in the study.

\section{Funding}

This work was supported by grants from National Key Basic Research Project (2012CB517503 and 2013CB530804), Health Special Scientific Research Project of Chinese People's Liberation Army (12BJZ34 and 14BJZ12), and Sanya Medical and Health Science and Technology Innovation Project (2016YW21)

\section{Availability of data and materials}

In attempt to preserve the privacy of patients, clinical data of patients will not be shared; data can be available from authors upon request.

\section{Authors' contributions}

Conceived and designed the experiments: SF, LL, PY. Performed the experiments: SF, LL, PY. Analyzed the data: SF, YL, LL, PY. Contributed reagents/materials/analysis tools: $S F, Y L, L L, P Y$. Wrote the paper: $S F, Y L$, $L L, P Y$. All authors read and approved the final manuscript.

\section{Competing interests}

The authors declare that they have no competing interests.

\section{Consent for publication}

Not applicable.

\section{Ethics approval and consent to participate}

The study protocol was approved by Ethics Committee of Chinese People's Liberation Army General Hospital (Beijing, China). Each participant provided written informed consent to be included in the study.

\section{Publisher's Note}

Springer Nature remains neutral with regard to jurisdictional claims in published maps and institutional affiliations.

\section{Author details}

'Department of Geriatric Cardiology, Chinese People's Liberation Army General Hospital, Beijing 100853, China. ${ }^{2}$ Department of Cardiology and Hainan Branch, Chinese People's Liberation Army General Hospital, Beijing, China.

Received: 30 December 2016 Accepted: 31 March 2017

Published online: 11 April 2017

\section{References}

1. Chen ZW, Chen LY, Dai HL, Chen JH, Fang LZ. Relationship between alanine aminotransferase levels and metabolic syndrome in nonalcoholic fatty liver disease. J Zhejiang Univ Sci B. 2008;9:616-22.
2. Tung $\mathrm{TH}$, Chang $\mathrm{TH}$, Chiu WH, et al. Clinical correlation of nonalcoholic fatty liver disease in a Chinese taxi drivers population in Taiwan: experience at a teaching hospital. BMC Res Notes. 2011:4:315.

3. Chen $\mathrm{CH}$, Huang $\mathrm{MH}$, Yang JC, et al. Prevalence and etiology of elevated serum alanine aminotransferase level in an adult population in Taiwan. J Gastroenterol Hepatol. 2007;22:1482-9.

4. Gholam PM, Flancbaum L, Machan JT, et al. Nonalcoholic fatty liver disease in severely obese subjects. Am J Gastroenterol. 2007;102:399-408.

5. Choi SY, Kim D, Kang JH, et al. Nonalcoholic fatty liver disease as a risk factor of cardiovascular disease: relation of non-alcoholic fatty liver disease to carotid atherosclerosis. Korean J Hepatol. 2008;14:77-88.

6. Fracanzani $A L$, Valenti $L$, Bugianesi $E$, et al. Risk of severe liver disease in nonalcoholic fatty liver disease with normal aminotransferase levels: a role for insulin resistance and diabetes. Hepatology. 2008;48:792-8.

7. Bedogni G, Bellentani S. Fatty liver: how frequent is it and why? Ann Hepatol. 2004;3:63-5.

8. Chen C, Lu FC, Department of Disease Control Ministry of Health, PR China. The guidelines for prevention and control of overweight and obesity in Chinese adults. Biomed Environ Sci. 2004;17 Suppl:1-36.

9. Alberti KG, Zimmet P, Shaw J, Epidemiology Task Force Consensus Group IDF. The metabolic syndrome: a new worldwide definition. Lancet. 2005:366:1059-62.

10. Yang SH, Dou KF, Song WJ. Prevalence of diabetes among men and women in China. N Engl J Med. 2010;362:2425-6.

11. Asmar R, Benetos A, Topouchian J, et al. Assessment of arterial distensibility by automatic pulse wave velocity measurement. Validation and clinical application studies. Hypertension. 1995;26:485-90.

12. Oh SY, Cho YK, Kang MS, et al. The association between increased alanine aminotransferase activity and metabolic factors in nonalcoholic fatty liver disease. Metabolism. 2006;55:1604-9.

13. Omagari K, Kadokawa Y, Masuda J, et al. Fatty liver in nonalcoholic non-overweight Japanase adults:incidence and clinical characteristics. J Gastroenterol Hepatol. 2002;17:1098-105.

14. Cheng HY, Wang HY, Chang WH, et al. Nonalcoholic fatty liver disease: prevalence, influence on age and sex, and relationship with metabolic syndrome and insulin resistance. Int J Gerontol. 2013;9:194-8.

15. Parekh S, Anania FA. Abnormal lipid and glucose metabolism in obesity: implications for nonalcoholic fatty liver disease. Gastroenterology. 2007:132:2191-207

16. Fan JG, Farrell GC. Epidemiology of non-alcoholic fatty liver disease in China. J Hepatol. 2009;50:204-10.

17. Huang MA, Greenson JK, Chao C, et al. One-year intense nutritional counseling results in histological improvement in patients with nonalcoholic steatohepatitis: a pilot study. Am J Gastroenterol. 2005;100:1072-81.

18. Kugelmas M, Hill DB, Vivian B, Marsano L, McClain CJ. Cytokines and NASH: a pilot study of the effects of lifestyle modification and vitamin $\mathrm{E}$. Hepatology. 2003;38:413-9.

19. Schafer S, Kantartzis K, Machann J, et al. Lifestyle intervention in individuals with normal versus impaired glucose tolerance. Eur J Clin Invest. 2007:37:535-43.

20. Hickman IJ, Jonsson JR, Prins JB, et al. Modest weight loss and physical activity in overweight patients with chronic liver disease results in sustained improvements in alanine aminotransferase, fasting insulin, and quality of life. Gut. 2004;53:413-9.

21. Vajro P, Mandato C, Franzese A, et al. Vitamin E treatment in pediatric obesity-related liver disease: a randomized study. J Pediatr Gastroenterol Nutr. 2004:38:48-55.

22. Marchesini G, Bugianesi E, Forlani G, et al. Nonalcoholic fatty liver, steatohepatitis, and the metabolic syndrome. Hepatology. 2003:37:917-23.

23. Gabriely I, Ma XH, Yang XM, et al. Removal of visceral fat prevents insulin resistance and glucose intolerance of aging: an adipokine-mediated process? Diabetes. 2002;51:2951-8. 